\title{
The application of the femtosecond laser in cataract surgery
}

\section{Piotr Kanclerz, Karolina Pluta}

Hygeia Clinic, Gdańsk Head: Piotr Kanclerz, MD, PhD

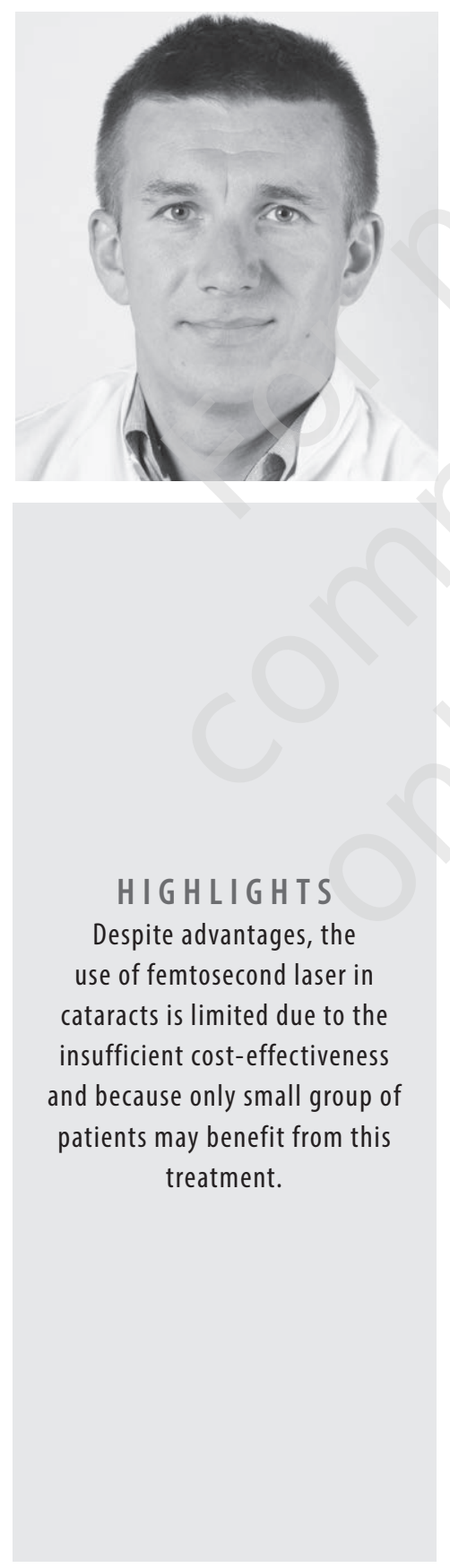

\section{ABSTRACT}

Introduction: Since the introduction, femtosecond laser-assisted cataract surgery (FLACS) was believed to revolutionize cataract surgery. However, the judgment of clinical benefits was found to be far more complex than initially might have been thought. The aim of this review was to analyze the benefits and drawbacks of FLACS compared to traditional phacoemulsification cataract surgery.

Results: The benefits of FLACS include lower cumulated phacoemulsification time and endothelial cell loss, perfect centration of the capsulotomy, and the possibility to perform precise femtosecond-assisted arcuate keratotomy incisions. The major disadvantages of FLACS are: high cost of the laser and the disposables for surgery, FLACS-specific intraoperative capsular complications, as well as the risk of intraoperative miosis and the learning curve.

Conclusions: FLACS seems to be beneficial in some groups of patients i.e., with low baseline endothelial cell count, or those planning to receive multifocal intraocular lenses. Nevertheless, having considered that the advantages of FLACS might not be clear in every routine case, it cannot be considered as cost-effective.

Key words: cataract surgery, femtosecond laser-assisted cataract surgery, phacoemulsification 


\section{INTRODUCTION}

Femtosecond lasers emit ultrashort, high-power pulses at infrared wavelength $(1053 \mathrm{~nm})$ to induce photodisruption or photoionization of biological tissues [1]. The introduction of femtosecond lasers to cataract surgery eliminated the problems associated with the use of ultrasound waves. However, clinical benefits of femtosecond lasers turned out to be much more complex than initially suspected.

The study aimed to review the benefits and drawbacks of femtosecond-laser-assisted cataract surgery (FLACS) as compared to conventional phacoemulsification cataract surgery (PCS).

\section{INTRAOPERATIVE ADVANTAGES AND DISADVANTAGES OF FLACS}

\section{Complications associated with laser docking}

Docking with FLACS requires additional steps, which are risky and time-consuming [2]. The most commonly reported difficulty associated with the use of the suction cup is the potential loss of suction and stoppage of the procedure, which may result in an incomplete capsulotomy or subconjunctival hemorrhage. In the study by Zhang et al., the completion rates of circular anterior capsulotomy, lens fragmentation and corneal incision were 98.6\% (95\% CI 97.8-99.1), 99.5\% (95\% CI 99.1-99.8), 97.6\% (95\% CI 96.798.3), respectively [3].

\section{Corneal incisions}

Clear corneal ports reduce the risk of complications during cataract surgery and allow good wound sealing [4]. However, morphological analysis of laser incision-specimens showed significantly higher count of apoptotic cells at the cutting edge compared to PCS [5]. Optical coherence tomography studies have shown that even though laser-constructed corneal incisions are more precise and manifest similar healing one month postoperatively, they present a slower adhesion of wound edges. Rodrigues et al. reported a partial loss of wound sealing in virtually all triplantar wounds made with the femtosecond laser and in only 44.6\% cases of manual incisions $(p=0.03)$ [6].

Another issue to be considered when comparing manual and femtosecond laser-assisted corneal incisions is the possibility of performing arcuate keratotomy (AK), which can be used to treat low-grade astigmatism during PCS. Moreover, with manual AK incisions there is a problem with relatively low predictability due to the limited reproducibility in incision length and axis alignment. Theoretically, femtosecond-assisted AK is easier, safer, and of greater reproducibility. However, it may cause some difficulties with correctly aligning the cylinder axis. In a study by Chan et al., the mean angle of error for AK was close to $0^{\circ}$, but the absolute angle of error was $17.5^{\circ} \pm 19.2^{\circ}$ [7].

\section{CAPSULOTOMY}

An important advantage of femtosecond laser capsulotomy (FLC) is the possibility to create a perfectly positioned and shaped capsulotomy. This would be a potentially important benefit in patients with multifocal intraocular lenses (IOLs) in which IOL centration might affect the visual performance. Panthier et al. found that the capsulotomy sizing was more precise in FLC than in manual continuous curvilinear capsulorhexis (CCC) [8]. Nevertheless, FLC did not improve the lens position or vision quality.

A problem with FLC is the strength of the capsular edge, which has been shown to decrease with increasing laser energy levels. However, even with optimized FLC energy settings, the edge of the capsulotomy presents a lower stress resistance and a greater tendency for anterior radial tears compared with CCC. An experimental study on human cadaver eyes showed that the fracture strength of the FLC is 1.28 times lower than in CCC [9]. As a consequence, clinically the rate of anterior capsule tears is higher in FLC $(1.84 \%)$ than in manual CCC $(0.22 \%)$ [10].

\section{The use of FLACS in advanced cataract surgery}

A significant difficulty of advances in the operation of advanced white cataracts is the performance of a perfect capsulorhexis. Problems encountered during this stage of the surgery include the absence of red reflex and increased intra-lens pressure, with the associated greater likelihood of damage to the anterior capsule. A pilot study showed potential advantages of FLACS in 25 operated eyes with advanced white cataracts, as the laser created a perfectly round capsulotomy of perfect size, which helped avoid intraoperative complications related to increased intracapsular pressure [11]. However, a significant problem in these cases may be the intraoperative outflow of milky white fluid into the anterior chamber, which may block the laser energy targeted on the lens capsule.

Studies analyzing the risk of intraoperative complications in patients with advanced white cataracts did not provide compelling evidence on the clinical benefits of FLACS over conventional PCS. In a large study on 132 eyes with advanced cataracts, Zhu et al. reported a lower risk of radial tears of the anterior capsule in FLACS than in manual PCS ( $0 \%$ vs. $12.1 \% ; \mathrm{p}=0.007)$. However, the risk of posterior lens capsular rupture (PCR), which is increased in advanced cataracts, did not differ between the FLACS and PCS groups (1.5\% vs. 6.1\%; $\mathrm{p}=0.362$ ) [12]. Therefore, additional studies are certainly needed to establish a definitive intraoperative advantage of FLACS over PCS. 


\section{Phacoemulsification energy and its influence on the endothelium}

Preliminary studies have shown that treatment with a femtosecond laser can shorten the effective phacoemulsification time (EPT) by $83.6 \%$ compared with conventional PCS [13]. Notably, the reduction in EPT might translate into a lower loss of endothelial cells. Subsequent studies have shown that FLACS helped minimize endothelial cell damage in particularly severe cataracts and provide faster visual rehabilitation than PCS $[14,15]$.

\section{Pupil size during surgery}

A significant problem and disadvantage of FLACS is intraoperative miosis. In a study by Nagy et al., the rate of intraoperative miosis amounted to $32 \%$ [16]. Risk factors for intraoperative miosis include longer time of laser pre-treatment and older age of a patient [17]. Non-steroidal anti-inflammatory drugs help prevent intraoperative miosis, thus reduce surgery duration and the need for pupil expansion devices [18].

\section{POSTOPERATIVE BENEFITS AND DRAWBACKS OF FLACS}

\section{Cystoid macular edema}

Cystoid macular edema (CME) is one of the most common late complications after cataract surgery [19]. Surgical manipulations lead to the diffusion of proinflammatory factors into the vitreous, which may disrupt the blood-retinal barrier. This results in an increased perifoveal capillary permeability, followed by macular edema. Because the FLACS procedure employs additional maneuvers (laser docking or applanation), there is a higher risk of CME. The first studies on the use of a femtosecond laser in cataract surgery showed a statistically higher incidence of CME in the FLACS than in conventional PCS $(0.8 \%$ vs. $0.2 \%$; $\mathrm{p}=0.07)$ [20]. In subsequent studies, stronger anti-inflammatory drugs were used to reduce the risk of CME. According to a recent Cochrane review, it is not possible to determine the equivalence or superiority of FLACS compared to PCS in terms of CME risk [21]. Therefore, there is still a need for sufficiently large studies.

\section{Posterior capsule opacification}

Femtosecond laser capsulotomy induces greater apoptosis of the lens epithelial cells located along the cutting edge compared with manual CCC [22]. The harmful apoptotic effect can be minimized by reducing energy levels of the laser [23]. Since the proliferation of lens epithelial cells after PCS is partly responsible for the posterior capsule opacifi- cation (PCO), theoretically the apoptotic effect of FLACS might negatively affect the formation of PCO [24]. However, in clinical trials, the PCO incidence in FLACS was not lower than in PCS.

\section{POSTOPERATIVE RESULTS}

Patients after FLACS showed a lower rate of refractive errors compared to those treated with conventional PCS. Moreover, in eyes with a shallow anterior chamber, FLACS generated less corneal edema and inflammation. However, in the European Registry of Quality Outcomes for Cataract and Refractive Surgery database, FLACS did not improve visual postoperative outcomes compared to routine PCS [25].

\section{Cost analysis}

When analyzing the total cost of a single FLACS case, several expenses should be considered: the cost of buying and maintaining the femtosecond laser, assistance from a trained technician, but also the amount of time required for additional FLACS steps. However, given that these costs are borne by the hospital and patients, FLACS cannot be considered cost-effective. In order to be cost-effective, FLACS should significantly reduce the complication rate and patients' costs [26].

\section{CONCLUSION}

FLACS may be considered beneficial in some groups of patients: those with low baseline endothelial cell count or those planning to use multifocal IOLs. Nevertheless, the advantages of FLACS are not clear in every routine case, so this method cannot be considered cost-effective. The advantages and disadvantages of the FLACS have been summarized in table 1.

\begin{tabular}{l|l}
\hline \multicolumn{1}{c}{1} & \multicolumn{1}{c}{\begin{tabular}{c} 
BABLE \\
\multicolumn{1}{c}{ Benefits and drawbacks of FLACS - summary. }
\end{tabular}} \\
\hline $\begin{array}{l}\text { lower time of cumulated } \\
\text { phacoemulsification and } \\
\text { endothelial cell loss }\end{array}$ & $\begin{array}{l}\text { high cost of the laser and } \\
\text { disposable materials }\end{array}$ \\
\hline $\begin{array}{l}\text { perfect capsulotomy centration } \\
\text { possibility to perform } \\
\text { femtosecond-assisted arcuate } \\
\text { keratotomy }\end{array}$ & FLACS-specific intraoperative \\
\hline
\end{tabular}

FLACS - femtosecond laser-assisted cataract surgery. 


\author{
CORRESPONDENCE \\ Piotr Kanclerz, MD, PhD \\ Hygeia Clinic \\ 80-286 Gdańsk, Jaśkowa Dolina 57 \\ tel.: +587764046 \\ e-mail: p.kanclerz@gumed.edu.pl
}

ORCID

Piotr Kanclerz - ID - http://orcid.org/0000-0002-8036-7691

Karolina Pluta - ID - http://orcid.org/0000-0003-1343-9947

\section{References}

1. Chung SH, Mazur E. Surgical applications of femtosecond lasers. J Biophotonics. 2009; 2(10): 557-72.

2. Feldman BH. Femtosecond laser will not be a standard method for cataract extraction ten years from now. Surv Ophthalmol. 2015; 60(4): 360-5. https://doi.org/10.1016/j.survophthal.2015.02.002.

3. Zhang X, Yu Y, Zhang G et al. Performance of femtosecond laser-assisted cataract surgery in Chinese patients with cataract: a prospective, multicenter, registry study. BMC Ophthalmol. 2019; 19(1): 77.

4. Alió JL, Abdou AA, Soria F et al. Femtosecond laser cataract incision morphology and corneal higher-order aberration analysis. J Refract Surg. 2013; 29(9): 590-5.

5. Mayer WJ, Klaproth OK, Hengerer FH et al. In vitro immunohistochemical and morphological observations of penetrating corneal incisions created by a femtosecond laser used for assisted intraocular lens surgery. J Cataract Refract Surg. 2014; 40(4): 632-8.

6. Rodrigues R, Dos Santos MS, Silver RE et al. Corneal incision architecture: VICTUS femtosecond laser vs manual keratome. Clin Ophthalmol. 2019; 13: 147-152. https://doi.org/10.2147/opth.s181144.

7. Chan TCY, Cheng GPM, Wang Z et al. Vector Analysis of Corneal Astigmatism After Combined Femtosecond-Assisted Phacoemulsification and Arcuate Keratotomy. Am J Ophthalmol. 2015; 160(2): 250-5.e2. https://doi.org/10.1016/j.ajo.2015.05.004.

8. Panthier C, Costantini F, Rigal-Sastourné JC et al. Change of Capsulotomy Over 1 Year in Femtosecond Laser-Assisted Cataract Surgery and Its Impact on Visual Quality. J Refract Surg. 2017; 33(1): 44-9.

9. Daya S, Chee S-P, Ti S-E et al. Comparison of anterior capsulotomy techniques: continuous curvilinear capsulorhexis, femtosecond laser-assisted capsulotomy and selective laser capsulotomy. Br J Ophthalmol. 2020; 104(3): 437-42.

10. Abell RG, Darian-Smith E, Kan JB et al. Femtosecond laser-assisted cataract surgery versus standard phacoemulsification cataract surgery: Outcomes and safety in more than 4000 cases at a single center. J Cataract Refr Surg. 2015; 41(1): 47-52. https://doi.org/10.1016/ j.jcrs.2014.06.025.

11. Conrad-Hengerer I, Hengerer FH, Joachim SC et al. Femtosecond laser-assisted cataract surgery in intumescent white cataracts. J Cataract Refract Surg. 2014; 40(1): 44-50. https://doi.org/10.1016/j.jcrs.2013.08.044.

12. ZhuY, Chen X, Chen $P$ et al. Lens capsule-related complications of femtosecond laser-assisted capsulotomy versus manual capsulorhexis for white cataracts. J Cataract Refract Surg. 2019; 45(3): 337-42. https://doi.org/10.1016/j.jcrs.2018.10.037.

13. Abell RG, Kerr NM, Vote BJ. Toward Zero Effective Phacoemulsification Time Using Femtosecond Laser Pretreatment. Ophthalmology. 2013; 120(5): 942-8. https://doi.org/10.1016/j.ophtha.2012.11.045.

14. Kanclerz P, Alio JL. The benefits and drawbacks of femtosecond laser-assisted cataract surgery. Eur J Ophthalmol. 2020. Online ahead of print. https://doi.org/10.1177/1120672120922448.

15. Piňero A, Kanclerz P, Barraquer RI et al. Evaluation of femtosecond laser-assisted cataract surgery after 10 years of clinical application. Arch Soc Esp Oftalmol. 2020; 95(11): 528-37.

16. Nagy ZZ, Takacs Al, Filkorn T et al. Complications of femtosecond laser-assisted cataract surgery. J Cataract Refract Surg. 2014; 40(1): 20-8.

17. Jun JH, Hwang KY, Chang SD et al. Pupil-size alterations induced by photodisruption during femtosecond laser-assisted cataract surgery. J Cataract Refract Surg. 2015; 41 (2): 278-85.

18. Walter K, Delwadia N, Coben J. Continuous intracameral phenylephrine-ketorolac irrigation for miosis prevention in femtosecond laser-assisted cataract surgery: Reduction in surgical time and iris manipulation. J Cataract Refract Surg. 2019; 45(4): 465-9. https://doi. org/10.1016/j.jcrs.2018.11.004.

19. Grzybowski A, Kanclerz P. The Role of Steroids and NSAIDs in Prevention and Treatment of Postsurgical Cystoid Macular Edema. Curr Pharm Des. 2018; 24(41): 4896-902.

20. Ewe SYP, Oakley CL, Abell RG et al. Cystoid macular edema after femtosecond laser-assisted versus phacoemulsification cataract surgery. J Cataract Refract Surg. 2015; 41(11): 2373-8. https://doi.org/10.1016/j.jcrs.2015.04.031.

21. Day AC, Gore DM, Bunce $C$ et al. Laser-assisted cataract surgery versus standard ultrasound phacoemulsification cataract surgery. Cochrane Database Syst Rev. 2016. https://doi.org/10.1002/14651858.cd010735.pub2. 
22. Mayer WJ, Klaproth OK, Ostovic M et al. Cell Death and Ultrastructural Morphology of Femtosecond Laser-Assisted Anterior Capsulotomy. Invest Ophthalmol Vis Sci. 2014; 55(2): 893. https://doi.org/10.1167/iovs.13-13343.

23. Sun W, Liu J, Li J et al. Human lens epithelial cell apoptosis and epithelial to mesenchymal transition in femtosecond laser-assisted cataract surgery. Int J Ophthalmol. 2018; 11(3): 401-7.

24. Pisciotta A, De Maria M, Verdina T et al. Anterior Capsule of the Lens: Comparison of Morphological Properties and Apoptosis Induction following FLACS and Standard Phacoemulsification Surgery. Biomed Res Int. 2018; 2018: 7242837.

25. Manning S, Barry P, Henry Y et al. Femtosecond laser-assisted cataract surgery versus standard phacoemulsification cataract surgery: Study from the European Registry of Quality Outcomes for Cataract and Refractive Surgery. J Cataract Refract Surg. 2016; 42(12): 1779-90. https://doi.org/10.1016/j.jcrs.2016.10.013.

26. Abell RG, Vote BJ. Cost-effectiveness of femtosecond laser-assisted cataract surgery versus phacoemulsification cataract surgery. Ophthalmology. 2014; 121(1): 10-6. 
The utility of the femtosecond laser in cataract surgery

P. Kanclerz, K. Pluta

\section{Authors' contributions:}

All authors contributed equally to the article.

Conflict of interest:

None.

Financial support:

None.

Ethics:

The content presented in the article complies with the principles of the Helsinki

Declaration, EU directives and harmonized requirements for biomedical journals. 